\title{
FABRICAÇÃO DE PLACAS DE CIRCUITO IMPRESSO: PROJETO DE EXTENSÃO PARA AUXÍLIO NO ENSINO DE ENGENHARIA ELÉTRICA E BIOMÉDICA
}

DOI: 10.37702/2175-957X.COBENGE.2021.3671

Wendler Luis Nogueira Matos - wendleerluis@gmail.com

Universidade Federal do Pará

Rua comandante Francisco de Assis 2793

68743-100 - Castanhal - PA

Adonis Ferreira Raiol Leal - adonisleal1@gmail.com

Universidade Federal do Para

Tv Mauriti 3206

66093-681 - Belem - PA

Gabriel Araujo da Silva - gabrielpastilhex@hotmail.com

Universidade Federal do Pará

Travessa do Chaco 2155

66093-542 - Belém - PA

Alex Henrique Sousa Santos - alex.henriquesantos27@gmail.com

Universidade Federal do Pará

Conjunto cohab, gleba 2, travessa A 160

66623-820 - Belém - PA

Resumo: O seguinte trabalho trata de uma descrição qualitativa do projeto de extensão intitulado "Fabricação de Placas de Circuito Impresso (PCI) pelo Método Fotográfico" e qual sua contribuição para o ensino de engenharia elétrica e biomédica. Os estudantes devem ter a experiência em projetar com qualidade placas de circuito para terem autonomia no desenvolvimento de protótipos tecnológicos. Nos cursos de engenharia elétrica e biomédica da Universidade Federal do Pará (UFPA) não se tem uma prática relacionada diretamente com a ideia abordada nesse trabalho, seja em uma matéria específica, seja opcional, por isso o caráter inovador do projeto de extensão criado. Os alunos precisam estar conectados a parte prática das engenharias; se o desenvolvimento da graduação se limitar aos assuntos da grade curricular oficial existirá uma lacuna entre teoria 
e prática profissional. O objetivo do trabalho é descrever a fabricação das placas e avaliar as respostas de um questionário respondido por alunos de cinco turmas do minicurso PCl, sendo quatro em 2019 e uma em 2020.

Palavras-chave: Placas de Circuito Impresso, Projeto de Extensão, Ensino de Engenharia Elétrica e Biomédica 


\section{FABRICAÇÃO DE PLACAS DE CIRCUITO IMPRESSO: PROJETO DE EXTENSÃO PARA AUXÍLIO NO ENSINO DE ENGENHARIA ELÉTRICA E BIOMÉDICA}

\section{INTRODUÇÃO}

Diversas matérias dos cursos de graduação de engenharia elétrica e biomédica necessitam da construção de placas de circuito impresso, como: eletrônica digital e analógica; sistemas de controle e circuitos elétricos. Por simplicidade, comumente se utiliza protoboard para inserção dos pinos dos dispositivos eletrônicos e circuitos integrados (SOUSA, 2018), mas em aplicações reais e práticas de engenharia necessitase de placas de circuito profissionais, nas quais os componentes são soldados. É importante, então, que os alunos tenham capacidade e conhecimento desde o projeto da placa em um software adequado e fabricação da mesma até a inserção e soldagem dos componentes.

Em aplicações de engenharia, muitas vezes se precisa confeccionar circuitos eletrônicos para processos de instrumentação, que usam dispositivos microcontrolados, sensores e outros equipamentos. A fabricação de Placas de Circuito Impresso $(\mathrm{PCl})$ pode ser feita de maneira industrial, a partir das CNC's (Controles Numéricos Computadorizados), ou a partir de produtos químicos e outras etapas mais simples, mas que podem obter ótimos resultados (RODRIGUES et al., 2019).

A extensão universitária faz parte do tripé que compõe uma universidade, juntamente com ensino e pesquisa. Jezine (2004) define que a extensão é uma relação entre teoria e prática a partir de um diálogo entre universidade e sociedade, objetivando trocar conhecimentos e experiências. Entretanto, projetos de extensão são atribuídos naturalmente a área de ciências humanas, pelo maior vínculo com sociedade e coletividade. Precisa-se formalizar mais essas práticas no campo das engenharias. É necessário então divulgar resultados dos impactos transformadores dessas atividades dentro dessa área de formação profissional (OLIVEIRA et al., 2018).

Além disso, de acordo com Santos (2016), é necessário estimular a reflexão entre teoria e prática, pois isso aprimora a formação do estudante de nível superior, pois na prática podem testar os conhecimentos que adquiriram na sala de aula. Esse foi um fator que motivou o projeto de extensão de $\mathrm{PCl}$, para que os alunos pudessem ter a oportunidade de conhecer um processo fundamental da atuação em engenharia elétrica e biomédica, já que existe uma infinidade de aplicações que precisam de circuitos elétricos e eletrônicos, seja nas indústrias, estações de energia elétrica, instalações hospitalares ou eletrodomésticos residenciais.

Os maiores índices de abandono de um curso superior no Brasil são observados no início da graduação. A evasão no primeiro ano chega a ser três vezes maior que nos anos posteriores (SILVA et al., 2007; PRIM; FÁVERO, 2013). É necessário então que a instituição como um todo e os professores/alunos reflitam sobre as ações institucionais tais como estrutura, ensino, pesquisa e extensão (ALVES; MANTOVANI, 2016). Essa é outra motivação para o projeto, sendo uma possível contribuição do mesmo poder incentivar mais projetos que visem ensinar sobre a realidade prática dos cursos de engenharia, para tentar diminuir a evasão dos alunos, que muitas vezes podem perder 0 interesse no curso devido à alta exigência de conhecimentos teóricos que muitas vezes não são usados com frequência no trabalho dia a dia dos profissionais. 
Para formalizar a ideia desenvolvida, procurou-se uma metodologia de ensino que focasse na relação entre teoria e prática. A metodologia Problem based Learning (PBL) Aprendizado Baseado em Projetos baseia-se no aprendizado com base em desafios e situações práticas de ensino. Quando se estuda a teoria é muito simples corrigir erros, mas na prática não necessárias habilidades e competências de projeto para que tudo ocorra como o esperado. Os alunos, que um dia serão profissionais, precisam saber resolver problemas a partir do conhecimento de muitas áreas diferentes (RIBEIRO, 2005).

O objetivo do trabalho é descrever a fabricação de placas de circuito impresso pelo método fotossensível, a partir de exemplos que estão contidos na apostila usada nos minicursos de $\mathrm{PCl}$, que foi o produto final do projeto de extensão. Além disso, os resultados do questionário que foi aplicado em 2021 são avaliados. A seção 2 aborda a metodologia do trabalho. A seção 3 apresenta os resultados do questionário respondido por alunos de 5 turmas do minicurso PCI. Por fim, a conclusão é apresentada na Seção 4.

\section{METODOLOGIA}

Os alunos do projeto de extensão intitulado "Fabricação de Placas de Circuito Impresso pelo Método Fotográfico", da Universidade Federal do Pará (UFPA), desenvolveram, durante o ano de 2019 e início de 2020, atividades cujo objetivo foi elaborar um material passo a passo sobre como construir as placas de circuito com a técnica da tinta fotossensível. Além disso, foi necessário elaborar/construir partes físicas para que fosse possível realizar todas as etapas de fabricação. Todos os materiais e mecanismos foram destinados ao Laboratório de Sistemas Eletrônicos (LSE), que possui participação tanto de alunos de engenharia elétrica quanto de biomédica. Um questionário seria disponibilizado em 2020, porém, com o início da pandemia da COVID-19 o projeto foi interrompido temporariamente. Assim, somente em 2021 foi elaborado e disponibilizado através do Google Forms.

O minicurso de PCl foi aplicado a 5 turmas, sendo 4 em 2019 e 1 no início de 2020. Um total de 40 alunos finalizaram e tiveram direito ao recebimento de certificado de participação. Quanto ao questionário enviado em 2021, 18 pessoas responderam as perguntas. Das 18, apenas $2(11,11 \%)$ eram de fora da UFPA, sendo do Centro Universitário do Estado do Pará (CESUPA). No questionário foram feitas várias perguntas para os alunos participantes do minicurso. O objetivo era avaliar o nível de conhecimento antes das aulas a respeito de fabricar placas com o método proposto, bem como a opinião deles sobre a organização, duração, dificuldade nos assuntos abordados e se existe a necessidade de mais atividades práticas dentro dos cursos de engenharia elétrica e biomédica na UFPA. Ao final foi feita uma pergunta descritiva para saber se o minicurso contribuiu para o aprendizado dos alunos. A seguir é apresentado o passo a passo da construção da PCl.

\subsection{Software Eagle}

Os designs dos circuitos eletrônicos foram desenvolvidos no software Eagle. Tratase de um programa computacional de desenho de placas de circuito impresso que possui uma grande quantidade de componentes eletrônicos e várias bibliotecas, possibilitando assim a criação de inúmeros circuitos (SILVA; MARCUS, 2019). O Eagle permite converter automaticamente o diagrama esquemático para o layout da $\mathrm{PCl}$ de modo prático e eficiente. $\mathrm{O}$ layout da $\mathrm{PCl}$ consiste no modelo da placa contendo as trilhas e as ilhas (que demarcam os furos de fixação dos componentes do circuito). O software tem algumas ferramentas, como: editor de diagramas (schematic editor), editor de layout (board editor) e o desenho automático das trilhas (autorouter) (DECLERQUE, 2014). 
O schematic editor é a área de desenvolvimento do diagrama elétrico da PCl. Esta ferramenta conta com todos os instrumentos necessários para projetar o circuito. Porém, o software Eagle não permite simular o funcionamento dos componentes, logo se faz necessário ter o conhecimento prévio sobre o que será projetado. A Figura 1 (a) mostra um circuito exemplo utilizado na aula. Concluída esta etapa, o projetista pode gerar o modelo inicial do layout da PCl por meio da ferramenta 'board editor' (DECLERQUE, 2014).

A ferramenta board editor é o local que permite a configuração do layout de placa, com as estruturas de edição das trilhas, ilhas e legendas. Um cuidado importante que deve ser levado em conta neste processo e que a sobreposição de trilhas pode comprometer o funcionamento real do circuito. Entretanto, o software Eagle conta com a ferramenta autorouter, que permite traçar as trilhas de interligação dos componentes de forma automática a partir de um padrão pré-definido. Todavia, ao final do processamento do autorouter o projetista deve realizar pequenos ajustes e adaptações. Por ser um processo automático, se mostra como uma importante ferramenta, uma vez que reduz consideravelmente o processo de confecção das placas no software, levando em conta o projeto de circuitos complexos (DECLERQUE, 2014). A Figura 1 (b) representa o circuito da Figura 1 (a) na etapa inicial de edição da placa.

Figura 1 - Circuito exemplo no Schematic editor (a) e no 'board editor' (b).

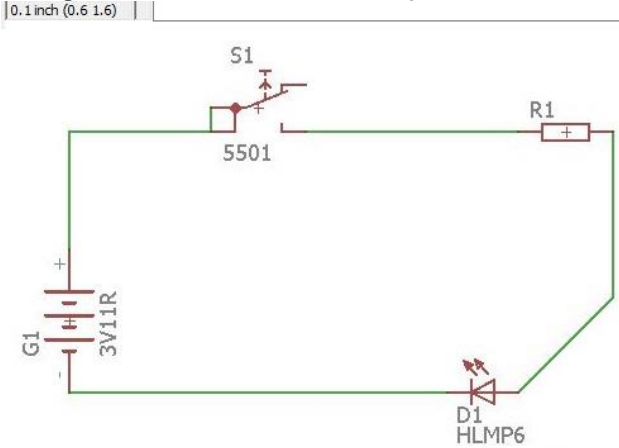

(a)

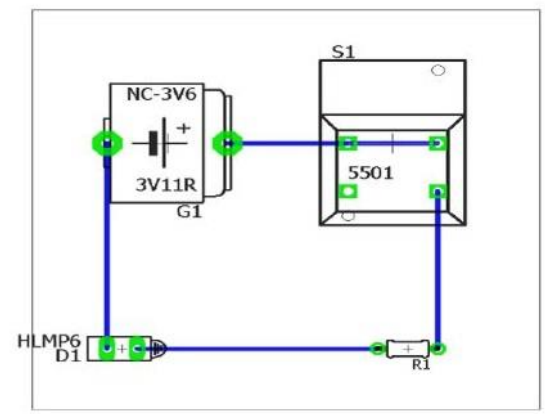

(b)

Fonte: Autores.

\subsection{Sugestões de Projeto}

Os alunos de todas as turmas do minicurso de Fabricação de Placas de Circuito Impresso possuíam duas sugestões de circuitos. Contudo, existia a liberdade para se desenvolver ideias próprias, contanto que o tamanho da placa não ultrapassasse $5 \times 5 \mathrm{~cm}^{2}$, com a observação da confiança do projetista no circuito em questão, tendo em vista que 0 software Eagle não realiza a simulação do funcionamento do mesmo.

\section{Botões com Leds}

Esse projeto consiste em um circuito com 3 leds (light-emitting diode), 3 botões, 3 resistores e um conector para a alimentação do circuito. Nesta sugestão, cada botão irá controlar o estado de um led correspondente. A Figura 2 (a) mostra o circuito na etapa de schematic editor e a Figura 2 (b) a etapa de board editor. Os componentes utilizados foram: Led (HLMP6); Resistor (R-US_0204/5), Conector (jumper jp1e e jp2e); Chave (switch 5501). 
Figura 2 - Esquemático (a) e circuito de placa (b) para o projeto dos Botões com Leds.

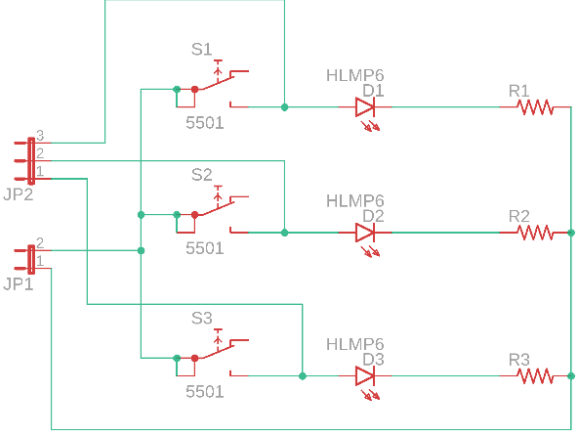

(a)

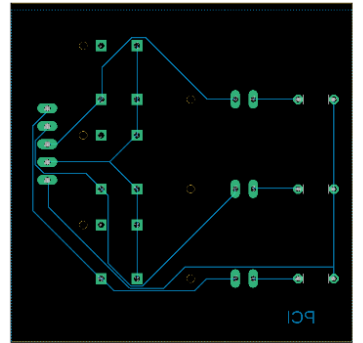

(b)

Fonte: Autores.

\section{Micro-piano}

A ideia é criar um pequeno piano a partir de sete notas musicais; para cada nota haverá um respectivo botão. Neste projeto de $\mathrm{PCI}$, um microcontrolador permitirá que o buzzer reproduza uma tonalidade musical. A Figura 3 (a) mostra o circuito na etapa de schematic editor e a Figura 3 (b) a etapa de board editor. Os componentes utilizados foram: Resistor (R-US_0204/5); Conector (jumper jp1e e jp2e); Chave (switch 5501); Buzzer (EB2209A). A seguir será detalhado todo o processo de confecção do layout da $\mathrm{PCl}$, desenvolvido no software Eagle.

Figura 3 - Esquemático (a) e circuito de placa (b) para o projeto Micro-piano.

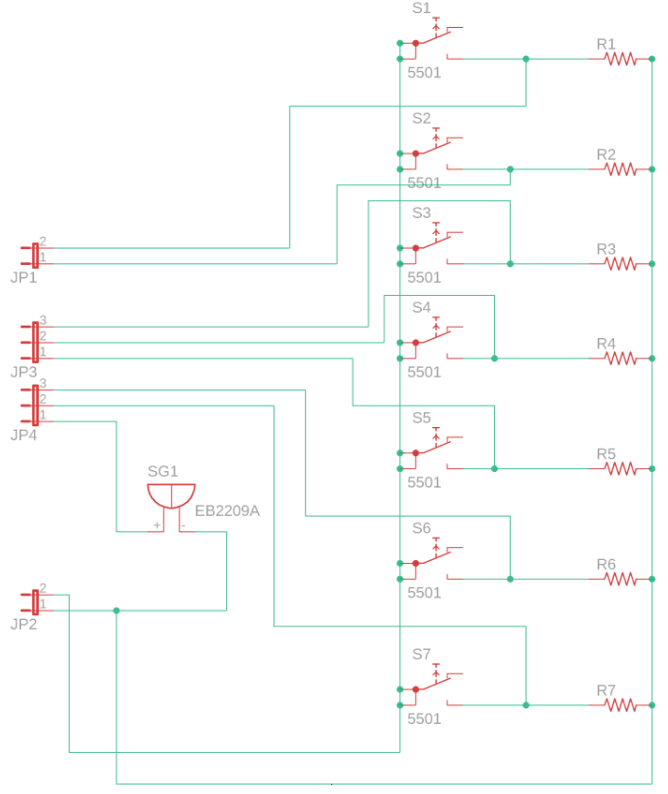

(a)

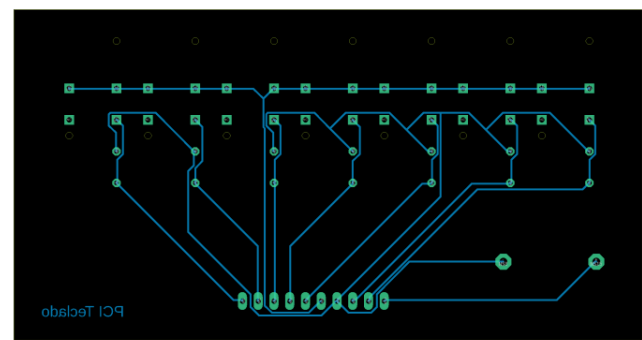

(b)

Fonte: Autores.

\subsection{Confecção do layout da PCI no software Eagle}

Para criar o layout da $\mathrm{PCl}$, primeiro deve-se desenvolver o esquemático do circuito na ferramenta schematic editor. Dentro desta área de desenvolvimento, utilizou-se a função addpart para adicionar os componentes do projeto. Feito isso, é necessário realizar as ligações entre os componentes, para tanto se usa a ferramenta line. Após a finalização do esquemático, transfere-se o circuito para a área board editor, onde o projeto inicial é transformado no circuito da placa. 
Neste momento, é preciso organizar os componentes do circuito e limitar o tamanho da placa, que para o minicurso a dimensão foi limitada a $5 \times 5 \mathrm{~cm}^{2}$ conforme mencionado anteriormente. Além disso, habilitando as camadas layers, names e values é acrescentado a legenda da placa. Em seguida, é editado as trilhas que fazem a conexão entre os componentes e para isso é usado o comando autorouter que possibilita o roteamento das trilhas de forma automática. Para o melhor funcionamento do circuito, é recomendado escolher o roteamento ao qual o software Eagle indicar $100 \%$ de desempenho. Ademais, ao se tratar de placas de circuito impresso, ângulos de $90^{\circ}$ formados pelo caminho das trilhas devem ser evitados, logo é recomendado selecionar roteamentos curvos. Outrossim, para se obter as ilhas, é utilizado os comandos polygon para delimitar a placa e em seguida ratsnest. Todavia, deve-se antes eliminar 0 roteamento das trilhas realizado anteriormente por meio da ferramenta delete.

Por último, é necessário salvar as imagens do layout da $\mathrm{PCl}$ que correspondem às trilhas, ilhas e legendas separadamente. Lembrando que todas as imagens necessitam ser salvas no formato monocromático. A impressão é realizada em papel transparente e denomina-se de fotolito.

\subsection{Confecção da placa de circuito impresso}

Primeiramente, para confeccionar a placa de circuito impresso, deve-se cortar a placa de fenolite com o tamanho ideal para o circuito o qual foi projetado no software Eagle. Após isso, é necessário lavar as placas com detergente para retirar toda mancha, gordura ou óleo que estiver sobre a placa usando uma palha de aço, pois qualquer sujeira pode impedir o contato elétrico entre os componentes.

\section{Pintura e secagem}

Depois da higienização da placa, é recomendado secar a placa de fenolite para que a tinta fotossensível consiga incorporar-se, corretamente, na placa (COELHO, 2020). Essa etapa deve ocorrer em um ambiente com a luminosidade bem baixa, pois a tinta utilizada é fotossensível. No início do projeto (primeira turma do minicurso), a pintura da placa era feita por meio de uma luva usando os dedos, tendo o cuidado de evitar sujeiras e impurezas nessa etapa. Ademais, precisava espalhar uma grande quantidade da tinta sobre a placa, concentrando uma quantidade maior no centro para que na etapa da centrifugação a placa apresentasse uma pintura uniforme.

Para as quatro turmas seguintes substituiu-se a centrífuga pelo aerógrafo, para reduzir desperdícios de tinta. Após essa etapa, recomenda-se deixar a placa secando por pelo menos um dia para um bom resultado na produção, haja vista que a tinta fotossensível demora um tempo considerável para secar.

\section{Confecção das trilhas}

Nesse momento, é preciso expor a placa à luz UV colocando o fotolito que contém o circuito projetado no software Eagle em cima da placa, por volta de 15 minutos. Em seguida, precisa-se preparar uma solução de barrilha usando a proporção de uma colher de sopa de barrilha para cada $400 \mathrm{~mL}$ de água. Essa solução de barrilha irá retirar a tinta da parte que não recebeu luz UV, para surtir efeito a placa precisa ficar na barrilha em torno de 2 a 4 minutos. A Figura 4 mostra a placa após a retirada da solução, com a devida revelação das trilhas. Após isso, deve-se confirmar o resultado das trilhas minimamente, pois se uma das trilhas estiver rompida ou fazendo contato com outra, temse que repetir a produção desde o começo. Lembrando que é recomendado repetir os processos de exposição a luz UV e banhar na solução de barrilha caso queria retirar finas camadas de tinta em determinadas partes da placa (MORGADO, 2014). 
Figura 4 - Resultado da placa após a retirada da solução de barrilha.

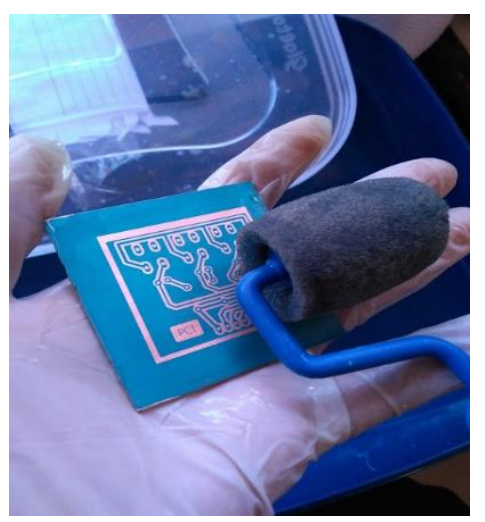

Fonte: Autores.

Por fim, é necessário banhar a placa na solução de percloreto de ferro para que ocorra a corrosão da parte de cobre exposta na placa e a formação das trilhas de contato da placa de circuito impresso. É preciso bastante atenção caso haja um erro após a corrosão, pois se caso tiver corroído uma trilha ou determinada parte importante para o circuito a placa será inutilizável, fazendo com que a confecção ocorra desde o início (MORGADO, 2014). Após retirar a placa do percloreto de ferro, deve-se lavar e, concluindo a confecção das trilhas, banhar a placa em uma solução de soda cáustica para retirar toda a tinta, preparando essa solução com cerca de $200 \mathrm{~mL}$ de água e duas colheres de soda cáustica.

\section{Confecção das ilhas}

Após terminar o processo de confecção das trilhas, tem-se que higienizar a placa novamente e repetir algumas etapas para o desenvolvimento das ilhas do circuito. É preciso realizar a pintura com o aerógrafo, esperar a tinta secar e expor a placa à luz UV colocando o fotolito que contém as ilhas projetadas no software Eagle em cima da placa. Então banhando a placa na mesma solução de barrilha, é obtido o resultado mostrado na Figura 5.

Figura 5 - Resultado da placa após a confecção das ilhas.

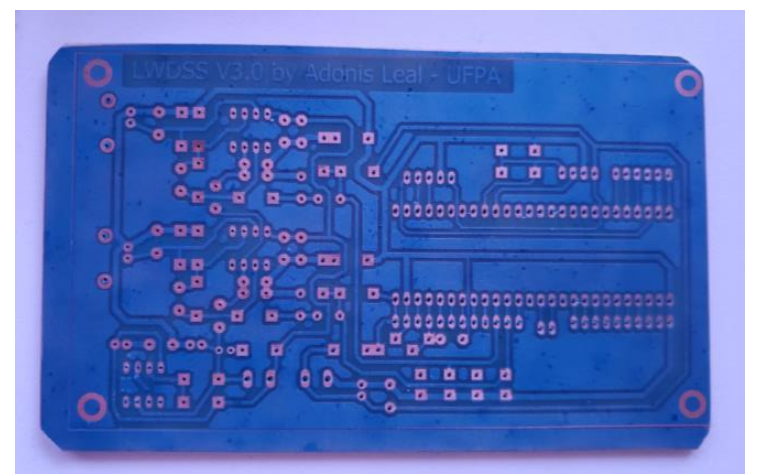

Fonte: Autores. 


\section{Legenda (opcional)}

O momento da legenda é opcional, servindo para a identificação e localização dos componentes na placa de circuito impresso. A fabricação da legenda é parecida com as etapas passadas, porém é feita na face oposta à que estava sendo usada para trilhas e ilhas. Após a pintura, deve-se esperar a tinta secar e expor a placa à luz UV colocando o fotolito que contém a legenda do circuito projetada no software Eagle em cima da placa. Por fim, é necessário banhar a placa na solução de barrilha para obter o resultado mostrado na Figura 6.

Figura 6 - Resultado da placa após a confecção das ilhas.

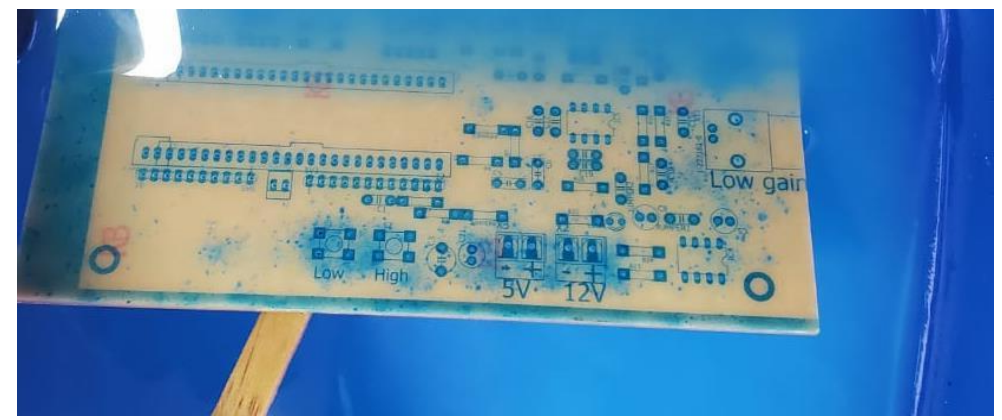

Fonte: Autores.

\section{$3 \quad$ RESULTADOS E DISCUSSÕES}

. A Figura 7 mostra os resultados acerca da pergunta "Qual era seu nível de conhecimento sobre fabricação de placas de circuito pelo método fotográfico antes de participar do minicurso?". Percebe-se que $77,8 \%$ não conheciam o método proposto pelo projeto de extensão. Além disso, $0 \%$ possuíam um conhecimento considerado "Ótimo" ou "Bom", expondo a importância e o grau de inovação do projeto de extensão.

Figura 7 - Resposta dos alunos sobre 0 conhecimento de fabricação de placas pelo método fotográfico antes do minicurso.

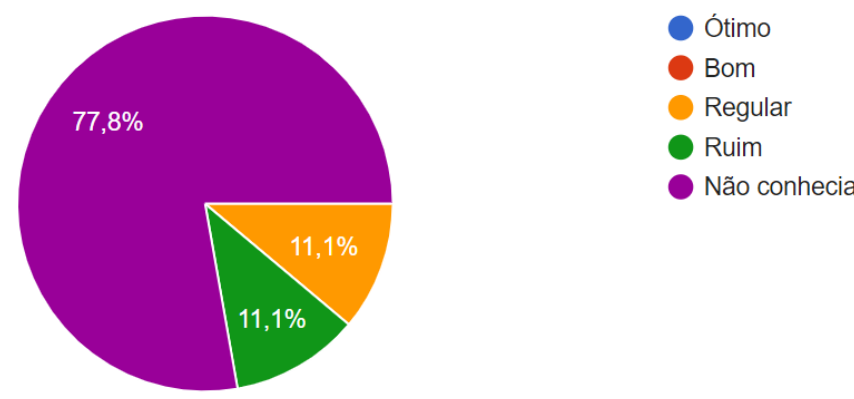

Fonte: Autores.

Quanto a pergunta "Você conhecia outro meio de fazer placas de circuito? Se sim, qual ou quais?", apenas 11,11\% (2 pessoas) responderam conhecer algum, sendo o método térmico, que faz uso de um ferro de passar roupa para transferir o conteúdo de trilhas e ilhas que foram impressos em papel transfer, para a placa de fenolite. Já para a 
pergunta "Quanto à organização do minicurso, como você classifica?", a Figura 8 mostra os resultados. Considera-se a estatística muito favorável e como um incentivo a continuação do projeto, pois $77,8 \%$ classificou como "Organizado", além de $22,2 \%$ como "Muito organizado". Ressalta-se a relevância em 0\% ter respondido "Desorganizado".

Figura 8 - Resposta dos alunos a respeito da organização do minicurso

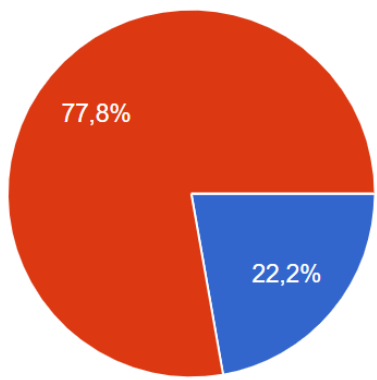

Fonte: Autores.

A Figura 9 expõe a distribuição para "Quanto à duração do minicurso e a sua aprendizagem, como você classifica?". Por necessitar de uma ampla teoria de entendimentos e projetos de circuitos elétricos, além de vários detalhes da parte prática que são importantes, esperava-se talvez que vários alunos pudessem classificar o minicurso como curto, porém $88,9 \%$ considerou a duração necessária para se entender o passo a passo da fabricação da placa, apenas $11,1 \%$ classificou como curto, necessitando de mais tempo para compreensão.

Figura 9 - Resposta dos alunos a respeito da duração do minicurso

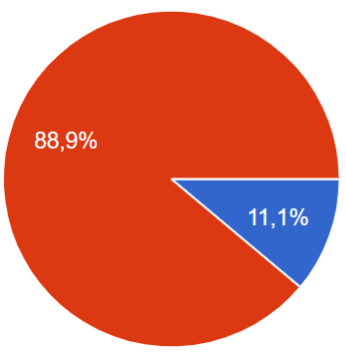

Fonte: Autores.
Curto, seria necessário um tempo maior para aprender os passos de modo adequado.

Duração necessária, tempo foi suficiente para abordar o passo a passo da fabricação

Longo, os assuntos e a prática poderiam ter sido ministrados em um tempo menor.

Algo muito importante é avaliar qual a percepção dos estudantes sobre as etapas de fabricação, objetivando avaliar as dificuldades e facilidades, para moldar a estrutura das próximas realizações da ação extensionista. A Figura 10 revela a escolha dos mesmos quanto a "Em qual tópico/processo você sentiu maior FACILIDADE?". Das possíveis opções é possível observar uma distribuição quase igualitária na classificação. $27,8 \%$ consideraram que a etapa mais fácil foi entender o procedimento dos filmes das trilhas, ilhas e legendas. Em seguida, um empate de 22,2\% tanto para a corrosão da placa no percloreto de ferro (haja vista que a única ação era mergulhar a placa na solução) como para o uso da centrífuga ou aerógrafo (inicialmente utilizou-se a centrífuga, mas depois substituiu-se para o aerógrafo, pela economia de tinta). 
Figura 10 - Resposta dos alunos a respeito de qual etapa foi a mais fácil.

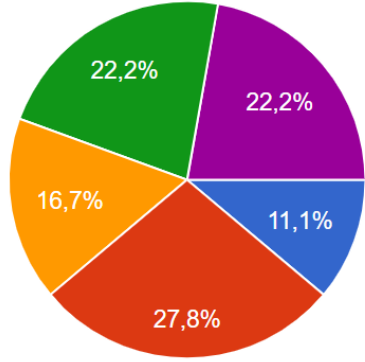

Fonte: Autores.

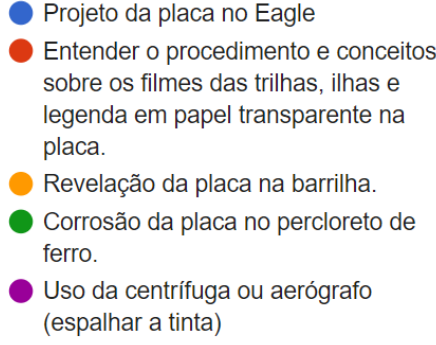

Uso da centrífuga ou aerógrafo (espalhar a tinta)

A Figura 11 mostra as respostas para "Em qual tópico/processo você sentiu maior DIFICULDADE?". A grande maioria, 61,1\%, consideraram que a parte mais difícil foi projetar o circuito no software Eagle, seja talvez pelo uso do próprio programa, com suas especificidades e etapas, seja por uma carência do próprio conhecimento na teoria de circuitos elétricos, já que no Eagle não é possível simular o que se projeta, necessitando de uma confiabilidade do projetista. Em segundo lugar, com 16,7\%, encontra-se a etapa de uso da centrífuga ou aerógrafo. A centrífuga foi usada apenas com a primeira turma do minicurso, em 2019. As outras 4 usaram o aerógrafo, então pode-se atribuir a tendência de dificuldade ao mesmo, provavelmente pelo fato de as vezes ocorrer entupimento do equipamento pela tinta, e ser necessário limpá-lo com uma determinada frequência.

Figura 11 - Resposta dos alunos a respeito de qual etapa foi a mais difícil.

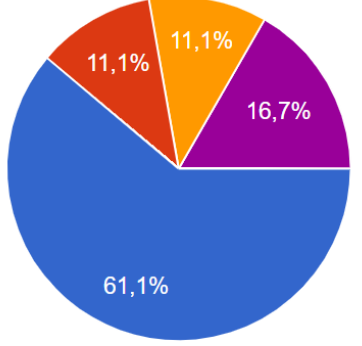

Fonte: Autores.

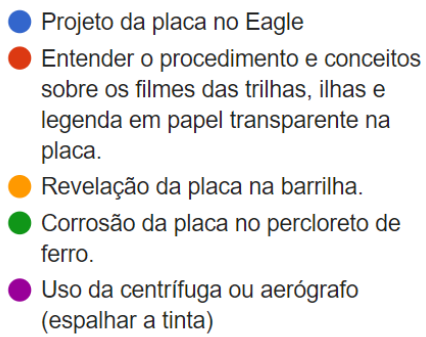

Uso da centrífuga ou aerógrafo (espalhar a tinta)

Quanto a pergunta "Em qual grau de dificuldade você considera o manuseio/utilização dos equipamentos e etapas da construção da placa, de modo geral?", temos a Figura 12 , na qual $55,6 \%$ concordaram em ser fácil o manuseio dos equipamentos, e apenas $5,6 \%$ consideraram difícil. A próxima pergunta foi descritiva, sendo "Você considera que a experiência no curso contribuiu para a ampliação de suas ideias sobre construir placas de circuito? Justifique.". O Quadro 1 mostra algumas das respostas. Das 18 pessoas, apenas 1 (5,55\%) respondeu "Não". 
Figura 12 - Resposta dos alunos a respeito da classificação da dificuldade no manuseio dos equipamentos.
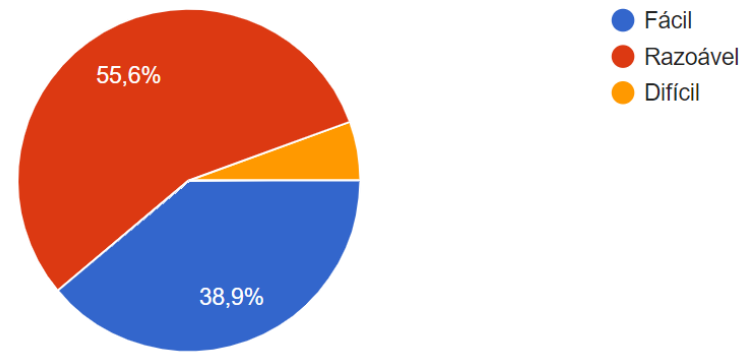

Difícil

Fonte: Autores.

Quadro 1 - Respostas sobre se o minicurso PCl contribuiu para ampliar as ideias sobre fabricar placas de circuito impresso.

"Sim, agora consigo compreender o processo de criação de uma placa, e quão essa ferramenta é útil."

"Sim! Não conhecia os métodos de construção de placas de circuito, então essa primeira experiência me inseriu nessa ideia e me fez gostar dela."

"Sim, até conhecer e fazer o mini curso, não tive nenhuma experiência com os placas de circuito impresso, o curso foi bom pra dar um norte e entender o passo a passo."

"Fabrico as placas dos meus projetos sempre que preciso. Foi de suma importância pra eu estar onde estou hoje."

"Sim, o curso é bastante acessível em sua linguagem e por isso a compreensão permite o estudante intuitivamente buscar aplicações para o projeto."

Fonte: Autores.

Considera-se muito positiva as respostas dos alunos. Como a pessoa que escreveu que o minicurso não contribuiu não justificou, infelizmente não pudemos avaliar as causas. A pergunta seguinte era "Qual sua avaliação para o minicurso?", cujos resultados são mostrados na Figura 13. 61,1\% classificou como "Bom" e 33,3\% como "Ótimo". Ressalta-se que $0 \%$ marcou a possibilidade "Ruim". Em seguida se considerou algo fundamental verificar com os alunos a seguinte situação: "Você considera importante e necessário que o ensino/aprendizagem de engenharia elétrica e biomédica tenha mais momentos práticos, de construir dispositivos/equipamentos, como nesse caso da oferta do minicurso para ensinar a construir circuitos reais e com qualidade profissional?". Como resposta, $100 \%$ dos estudantes confirmaram que "Sim", momentos de exercício prático são fundamentais na área de engenharia elétrica e biomédica, como no caso do minicurso PCl.

Figura 13 - Avaliação do minicurso pelos alunos.

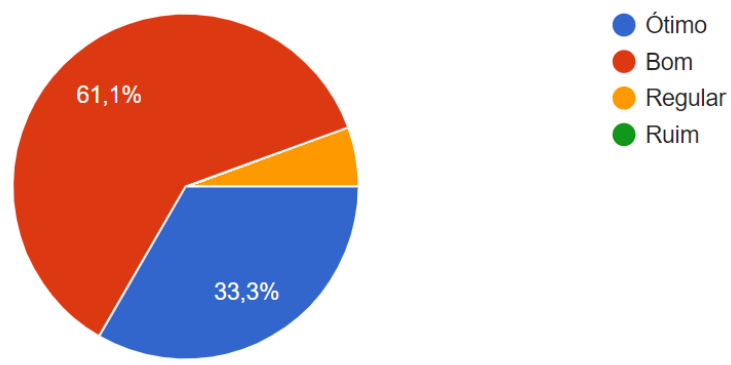

Fonte: Autores. 


\section{Conclusão}

O seguinte trabalho apresentou a descrição qualitativa do projeto de extensão "Placa de Circuito Impresso (PCl) pelo método fotográfico", que foi apresentado aos alunos de graduação em engenharia elétrica e biomédica da Universidade Federal do Pará (UFPA) por meio de minicursos, que foram oferecidos 5 vezes, sendo 4 em 2019 e 1 em 2020. As aulas foram realizadas no Laboratório de Sistemas Eletrônicos (LSE), local onde se encontram todos os equipamentos e materiais necessários para a confecção das placas. Teve-se um total de 40 alunos, sendo que 18 responderam ao questionário disponibilizado de modo online na plataforma Google Forms, durante o ano de 2021. $77,8 \%$ dos alunos responderam que não conheciam essa técnica de fabricação. $77,8 \%$ classificaram o minicurso como "Organizado" e $88,9 \%$ que teve a duração necessária para o entendimento do passo-a-passo, não sendo nem longo nem curto. 27,8\% consideraram a parte mais fácil o entendimento do processo de criação das ilhas, trilhas e legenda do circuito. Em outra pergunta, $61,1 \%$ consideraram mais difícil 0 desenvolvimento do circuito no software Eagle. 55,6\% classificaram como "Razoável" a dificuldade no processo de modo geral. $33,3 \%$ avaliaram o minicurso como "Ótimo" e $100 \%$ concordou em ser necessário mais momentos práticos no curso de engenharia elétrica e biomédica. Além disso, pelas respostas apresentadas sobre se o minicurso contribuiu para ampliar as ideias a respeito de placas de circuito considera-se que o projeto de extensão teve êxito. Incentiva-se a adoção de projetos e minicursos que possam aproximar os alunos da parte prática de seus cursos, para que se tornem profissionais mais qualificados para atuar no mercado de trabalho.

\section{REFERÊNCIAS}

ALVES, M. F. S. MANTOVANI, K. L. Identificação do Perfil dos Acadêmicos de Engenharia como uma Medida de Combate á Evasão. Revista de Ensino de Engenharia, v.35, n.2, p.26-36 - ISSN $0101-5001.2016$.

COELHO, I. Como fazer uma placa de circuito impresso de forma caseira. Disponível em: https://www.filipeflop.com/blog/como-fazer-uma-placa-de-circuito-impresso/. Acesso em: 20 abr. 2021.

DECLERQUE, M. S. Automação e Monitoramento Remoto Residencial. 2014. Trabalho de Conclusão de Curso - Curso Superior de Tecnologia em Redes de Computadores. Universidade Federal de Santa Maria, Rio Grande do Sul.

JEZINE, E. As práticas curriculares e a extensão universitária. Congresso Brasileiro de Extensão Universitária. Vol. 2. 2004.

OLIVEIRA, V. L. C. CAMPOS, R. M. V. SILVA, F. V. M. MONTEIRO, L. H. F. CAETANO, C. E. C. GONÇALVES, G. R. SOUZA, L. L. G. BARROS, J. A. N . M. CUNHA, C. R. Como um Projeto de Extensão pode Transformar o Perfil de um Aluno de Engenharia? XLVI Congresso Brasileiro de Educação em Engenharia e 1ํㅗ Simpósio Internacional de Educação em Engenharia. 2018.

PRIM, A. L.; FÁVERO, J. D. Motivos da evasão escolar nos cursos de ensino superior de uma faculdade na cidade de Blumenau. E-Tech: Tecnologias para Competitividade Industrial, Florianópolis, n. Especial Educação, p. 53-72, 2013. 
RIBEIRO, L. R. C. A Aprendizagem Baseada em Problemas (PBL): uma implementação na educação em engenharia na voz dos atores. 2005. f209 Tese (Doutorado em Educação) - Universidade Federal de São Carlos, São Carlos, 2005.

RODRIGUES, L. M. ALBUQUERQUE, M. P. PEREIRA, A. L. M. AZZI, G. Fabricação de Placa de Circuito Impresso (PCl) usando Método Fotográfico e Redução Significativa de Soluções Químicas. Notas Técnicas, v.9, n.3, p.26-33, 2019. dx.doi.org/10.7437/NT22367640/2019.03.009

SANTOS, J.H.S. (2016). Extensão Universitária e Formação no Ensino Superior. Revista Brasileira de Extensão Universitária, v. 7, n. 1, p.23-28 jan. - jun. 2016.

SILVA FILHO, R. L. L. et al. A evasão no ensino superior brasileiro. Cadernos de Pesquisa, v. 37, n. 132, p. 641- 659, set./dez. 2007.

SILVA, L. F; MARCUS, T. CNC Caseira Controlada por um Software Embarcado Open Source. 2019. Fundação Presidente Antônio Carlos de Conselheiro Lafaiete, Minas Gerais.

SOUSA, J. A. F. Abordagem Experimental para Aulas de Circuitos de Corrente Contínua Utilizando Placa Protoboard em Turmas do Ensino Médio. 2018. Tese (Mestrado) - Curso de Física. Universidade Federal Rural do Semi-Árido, Rio Grande do Norte. 2018.

Disponível em:

<https://repositorio.ufersa.edu.br/bitstream/prefix/5414/1/Jos\%c3\%a9AFS_DISSERT.pdf>. Acesso em: 15 abr, 2021.

\title{
MANUFACTURE OF PRINTED CIRCUIT BOARDS: EXTENSION PROJECT FOR AID IN THE TEACHING OF ELECTRICAL AND BIOMEDICAL ENGINEERING
}

\begin{abstract}
The following work deals with a qualitative description of the extension project entitled "Manufacture of Printed Circuit Boards (PCI) by the Photographic Method" and its contribution to the teaching of electrical and biomedical engineering. Students must have experience in designing circuit boards with quality to have autonomy in the development of technological prototypes. In the electrical and biomedical engineering courses at the Federal University of Pará (UFPA), there is no practice directly related to the idea addressed in this work, whether in a specific subject, or optional, that is why the innovative character of the extension project created. Students need to be connected to the practical part of engineering; if the undergraduate development is limited to the subjects of the official curriculum, there will be a gap between theory and professional practice. The objective of the work is to describe the manufacture of the boards and evaluate the responses to a questionnaire answered by students from five classes of the $\mathrm{PCl}$ minicourse, four in 2019 and one in 2020.
\end{abstract}

Keywords: Printed Circuit Boards, Extension Project, Teaching of Electrical and Biomedical Engineering. 